RUNNING HEAD: Congenital anomaly in the baby: parental reactions

\author{
RESEARCH ARTICLE
}

\title{
Patterns of parental emotional reactions after a pre- or postnatal diagnosis of a congenital anomaly
}

\author{
Ana Fonseca, Bárbara Nazaré, and Maria Cristina Canavarro \\ Faculty of Psychology and Educational Sciences, University of Coimbra, Portugal.
}

\section{Full address for correspondence:}

Ana Dias da Fonseca, Faculdade de Psicologia e Ciências da Educação, Rua do Colégio

Novo, Apartado 6153, 3001-802 Coimbra, Portugal

Email: ana.fonseca77@gmail.com

Telephone number: +351917727709

\section{Acknowledgements}

This study is part of the "Reproductive decisions and transition to parenthood after a pre- or postnatal diagnosis of congenital anomaly" research project, integrated in the Relationships, Development \& Health Research Group of the R\&D Unit Institute of Cognitive Psychology, Vocational and Social Development of the University of Coimbra (FEDER/POCTI-SFA-160192). Ana Fonseca and Bárbara Nazaré are supported by PhD Scholarships from the Portuguese Foundation for Science and Technology (SFRH/BD/47053/2008, SFRH/BD/43204/2008, respectively). The authors wish to thank the services that enabled the sample collection: Pediatric Cardiology Service of the Pediatric Hospital - Centro Hospitalar de Coimbra (parents of babies with congenital heart disease) and the Obstetrics and Neonatology Departments Hospitais da Universidade de Coimbra (the remaining participants from the clinical group). 


\title{
Patterns of parental emotional reactions after a pre- or postnatal
}

\author{
diagnosis of a congenital anomaly
}

\begin{abstract}
Objective: This study aimed to describe parental reactions at disclosure of a diagnosis of congenital anomaly and to investigate both the existence of distinct patterns of intensity of reactions and their association with post-diagnosis psychosymptomatology.

Background: When receiving the news of a pre- or postnatal diagnosis of congenital anomaly, parents usually display acute grief reactions. However, questions arise regarding the variability and intensity of those reactions and their clinical significance.

Method: 51 women and 42 men whose infants were diagnosed with a congenital anomaly answered, one-month after the disclosure, the Brief Symptom Inventory-18 and retrospectively evaluated their emotional experience at disclosure.

Results: Negative emotions, and also hope, were experienced with greater intensity at disclosure. There was variability of emotional reactions, as two distinct patterns were identified: one pattern fits the acute grief reactions pattern, and another of less intense emotional reactions. No gender differences were found on emotional reactions. Higher-intensity reactions at disclosure were associated with more psychosymptomatology one-month later only for fathers. Conclusion: Findings suggest the need for healthcare professionals to adjust their practice to meet parental needs in the early post-diagnosis stage. Both parents should be given the opportunity to express their emotions as a couple and individually.
\end{abstract}

Key-words: congenital anomaly; disclosure; prenatal diagnosis; postnatal diagnosis; parental emotional reactions; psychopathological symptoms.

\section{Introduction}

The public health impact of congenital anomalies is widely recognised as the leading cause of infant mortality and morbidity. The increased medical demands of caring for a infant with a diagnosis of congenital anomaly (DCA) may have financial, social, and emotional costs for the parents (Mazer et al., 2008). As such, the pre- or postnatal diagnosis disclosure triggers a set of parental emotional reactions (Statham, Solomou, \& Chitty, 2000). This study aimed to examine both maternal and paternal emotional 
reactions following the diagnosis disclosure and to evaluate their association with psychopathological symptoms in the early post-diagnosis stage. This information can help health professionals to recognise the most common reactions (Statham et al., 2000), and to tailor their practice to meet parental needs in the period immediately following the disclosure (Aite et al., 2004).

A growing body of research has sought to characterise parental reactions at the time of the disclosure of the DCA, which is often unexpected for parents (Mitchell, 2004) and forces them to face a great deal of new and frightening information (Aite, Zaccara, Trucchi et al., 2006). Unpreparedness to receive the news of the diagnosis results from the lack of early indicators that something might be wrong with the infant or from previous successful experiences (e.g., previous healthy child, absence of family history of congenital anomaly (e.g., Lalor \& Begley, 2006).

Research has shown that parents remember vividly the circumstances of the disclosure and describe their reactions in great detail (Drotar, Baskiewicz, Irvin, Kennell, \& Klaus, 1975). Regardless of the type of congenital anomaly, the range of parental emotional reactions seems to reflect a grief response (Chaplin, Schwitzer, \& Perkoulidis, 2005; Kerr \& McIntosh, 1998) because the diagnosis is often conceptualised as the loss of a healthy child (Jones, Statham, \& Solomou, 2005). The initial emotional reactions are described as overwhelming and intense (Drotar et al., 1975; Lalor, Begley, \& Galavan, 2009), and they are frequently composed of conflicting feelings (Graungaard \& Skov, 2007; Jones et al., 2005).

Predominantly negative emotional reactions are described in the studies. Commonly mentioned reactions include shock (Chaplin et al., 2005; Drotar et al., 1975; Lalor et al., 2009); sadness and anxiety (Aite, Zaccara, Nahom et al., 2006; Lalor et al., 2009; Petrucelli, Walker, \& Schorry, 1998); anger, guilt, despair, and frustration 
(Chaplin et al., 2005; Kerr \& McIntosh, 1998; Petrucelli et al., 1998); and less frequently, shame (Griffin, 2002).

Less often reported are positive emotions like relief (when a prognosis and treatment options are presented) (Petrucelli et al., 1998) and hope, which may be associated with the parental belief that their infant will manage well, despite the DCA, or with the expectation that the diagnosis was a mistake (Johansson \& Ringsberg, 2004; Sommerseth \& Sundby, 2010).

Although research has focused separately on parental reactions to a pre- (e.g., Aite et al., 2006; Chaplin et al., 2005) or postnatal diagnosis (e.g., Drotar et al. 1975; Kerr \& McIntosh, 1998), Aite et al. (2006) reported that "the hypothetical model proposed by Drotar to describe the adaptation of parents to the birth of an infant with a congenital malformation is applicable to prenatal age" (p. 652); those studies described similar initial reactions, characterised by intense and negative emotions. Also, Nusbaum et al. (2008) found that, regardless of the timing of the DCA, similar emotional reactions were found at disclosure.

Findings concerning parental emotional reactions to the DCA stem from research using qualitative designs (e.g., Aite et al., 2006), with an almost exclusive focus on maternal experiences (e.g., Lalor et al., 2009) and with great variability in the time elapsed from diagnosis to assessment (e.g., Drotar et al., 1975). Despite these limitations, as Statham et al. (2000) described, existing research highlights a predominant pattern "compatible with most acute grief reactions" (p. 733) following the DCA disclosure; common emotions experienced within acute grief reactions are deep shock, sadness, anxiety, anger, and despair, which may manifest in a set of behavioural and physiological responses (crying, isolation, sleeping and eating problems) (e.g., Chaplin et al., 2005). However, the authors (Statham et al., 2000) also mentioned that 
several issues require further study, including the variability in parental reactions and the association of those reactions with more adverse psychological effects.

Differences have been found in the frequency with which different emotions are reported (e.g., Petrucelli et al., 1998, found that all parents reported fear and sadness, approximately $70 \%$ reported frustration, and only 50\% reported anger and guilt). However, given the qualitative nature of most studies, it is unknown whether parents experience every emotion with the same intensity and whether these differences have clinical significance, i.e., whether they should be given particular attention by health professionals, as they may be indicative of current or future maladjustment. Additionally, the place of positive emotions described as parental emotional reactions to the DCA is also unclear because they do not fit the pattern of acute grief reactions. Thus, one of the goals of this study was to contribute to the knowledge of the variability in parental emotional reactions to the DCA.

There is growing consensus of the importance of fathers' experiences during pregnancy (Locock \& Alexander, 2006) and the detrimental effects of intracouple incongruent reactions to a stress-inducing event (Marshak \& Prezant, 2007). However, paternal reactions to the DCA have been scarcely explored, unlike the reactions of mothers, even in studies that comprised men (e.g., Drotar et al., 1975). Two existing studies revealed a similar pattern of reactions in mothers and fathers, although the latter did not mention guilt, and fathers overall reported less intense emotional reactions than did mothers (Kerr \& McIntosh, 1998; Schuth, Karck, Wilhelm, \& Reish, 1994). Locock and Alexander (2006) suggested that men try to assume a protective role with their partners during the diagnosis process by remaining optimistic or by containing their own emotions. Similarly, in the context of parental bereavement research, the concept of incongruent grief was developed to describe the differences between maternal and 
paternal grief responses. Mothers were found to have more intense grief responses after the loss of their infant, and to express their suffering more, while men tend to exert more control over their emotional expression (e.g., Goldbach, Dunn, Toedter, \& Lasker, 1991; Lang, Gottlieb, \& Amsel, 2001).

Parental emotional reactions to the DCA are expected to be related to their early post-diagnosis emotional adjustment (i.e., psychopathological symptoms), as Taanila, Syrjälä, Kokkonen, and Järvelin (2002) showed that the first moments and days after being informed of their child's disability were critical in determining the family's adaptation process. Several studies described a process of gradual adjustment to the diagnosis (Lalor et al., 2009), although some parents may face difficulties. For example, approximately one month after the DCA, Doherty et al. (2009) found clinically significant levels of psychopathological symptoms in $33 \%$ of mothers and $18 \%$ of fathers; another study found that, approximately one week after the diagnosis, parents of children with congenital heart disease experienced higher levels of distress when compared to norms. Unlike the first study, this study has found no gender differences in the proportion of clinically significant psychopathological symptoms (Brosig, Whitstone, Frommelt, Frisbee, \& Leuthner, 2007).

Few prospective longitudinal studies have assessed the emotional adjustment of parents, over time, after a DCA. However, the existent studies showed that adjustment in the early post-diagnosis stage predicted parental adjustment in later evaluations (e.g., six months after the birth of the infant, Skari et al., 2006). Furthermore, even where there was a decrease in the levels of psychopathological symptoms over time, they tended to keep significantly higher than the normative values (Brisch et al., 2003; Brosig et al., 2007). Similar results were found in a longitudinal study on the impact of a perinatal loss in maternal psychopathological symptoms. Specifically, it was found 
that the vast majority of mothers who presented clinically significant anxiety and depression symptoms in later assessments (8, 15 and 30 months post-loss) had also shown clinically significant scores of psychological distress in the initial assessment (2 months post-loss). This suggests that women who experience chronic distress after a perinatal loss, tend to present clinical levels of psychopathological symptoms in the early post-loss period; as such, a clinical evaluation at this time point becomes crucial in order to identify mothers at risk for long-term mental health problems (Boyle, Vance, Najman, \& Thearle, 1996).

Considering this, the early post-diagnosis stage may be a privileged period for risk situations to be identified by health professionals (in follow-up obstetric or paediatric appointments, after the DCA disclosure) and targeted for specialised counselling. While needing to deal with a grieving process for the loss of their healthy infant (e.g., Chaplin et al., 2005; Jones et al., 2005), parents simultaneously have to manage other issues associated with the DCA (e.g., treatment decisions, information about the DCA, the caregiving demands of an infant with a DCA; Howard, 2006). As coping with these multiple stressors may be more difficult in the presence of emotional maladjustment, it is important to understand the relationship between the intensity of emotional reactions at disclosure and the early post-diagnosis stage adjustment, which, to our knowledge, has not been previously explored. In this study, this association was investigated.

In summary, this study aimed: 1) to characterise parental emotional reactions at the disclosure, considering the frequency and intensity of emotions and the existence of different patterns of intensity of emotional reactions; 2) to investigate gender differences on emotional reactions at the disclosure; and 3) to investigate whether 
emotional reactions at the disclosure influenced the presence of psychopathological symptoms, one month after the diagnosis, for both mothers and fathers.

Based on the literature review, we expect that: Hypothesis 1) reactions of shock, sadness and anxiety will be experienced more frequently and with higher intensity, while other emotions such as shame, relief, or hope, will be less frequent and less intense; Hypothesis 2) there will be variability in the intensity of emotional reactions (more than one pattern of reactions); Hypothesis 3) women will present more-intense emotional reactions than will men; and Hypothesis 4) more-intense negative emotional reactions will be associated with more psychopathological symptoms for both mothers and fathers.

\section{Methods}

\section{Participants and procedure}

This study was approved by the Ethics Committees of the Hospitais da Universidade de Coimbra (HUC) and Centro Hospitalar de Coimbra (CHC), two Portuguese urban reference hospitals. Inclusion criteria for the present study were: parents whose infant was pre- or postnatally diagnosed with a congenital anomaly, without the occurrence of perinatal death or without the legal possibility of terminating the pregnancy, and a level of literacy that allowed the comprehension of the assessment protocol.

Between September 2009 and January 2011, the sample collection took place in the Obstetrics and Neonatology Departments of HUC; parents of infants with congenital heart disease were contacted in the Paediatric Cardiology Service of the Paediatric Hospital (CHC). Approximately one month after the disclosure of the DCA, all parents (consecutive sampling) were informed by the medical team about this investigation at the end of a medical appointment, and their authorisation to be contacted by the 
researchers was sought. The research goals were presented to all parents contacted, and an informed consent form was signed by those parents who agreed to participate. Participants were given the questionnaires, and were asked to return them to the researchers at their next medical appointment [average time until return: $M(S D)=$ 21.84 (12.57) days].

A total of 69 couples were contacted, of whom 18 refused to participate/did not return the questionnaires (participation rate $=74 \%$ ). Of the remaining 51 couples, the questionnaires were returned by both members of 42 couples $(82.4 \%)$ and only by women in eight cases $(17.6 \%)$.

The final sample comprised 93 participants (54.8\% were women). Demographic and clinical data for the sample are presented in Table 1. There were no gender differences in demographic data, with exception of educational level: on average, women had studied longer than men.

(Table_1_about_here)

\section{Measures}

Sociodemographic (gender, age, marital status, educational level, and professional status) and clinical information about the infant's DCA (type of DCA according to the European Surveillance of Congenital Anomalies [EUROCAT] categorisation, 2009; timing of diagnosis [pre- vs. postnatal]) were collected.

Emotional reactions to the diagnosis disclosure were evaluated with a question developed by the authors: "When you learned of your infant's diagnosis, how much did you feel the following emotions?", which was similar to the one used in the study by Petrucelli et al. (1998). However, instead of an ordinal scale, we adopted visual analogue scales (from $0=I$ did not feel it at all to $100=I$ felt it a lot), in order to assess 
the presence and magnitude of several emotions at a given time. Visual analogue scales are used to measure constructs that are believed to range in a continuum of values, rather than in discrete categories (ordinal scales). Based on a literature review of emotional reactions to a DCA (Fonseca \& Canavarro, 2010), ten emotions were listed (negative: guilt, anger, sadness, anxiety, shock, despair, shame, frustration; and positive: relief, hope). The alpha coefficient in our sample was .81.

The Portuguese version of the Brief Symptom Inventory-18 (BSI-18) (Canavarro, 2007) was used to measure psychosymptomatology (5-point Likert scale ranging from $0=$ Not at all to $4=$ Extremely). The Global Distress Index (GDI) was computed based on the sum of the three dimensions of the inventory (anxiety, depression, and somatisation) and was used in our study given its informative value. Cronbach's alpha for the GDI in our sample was .94.

\section{Statistics}

Analyses were conducted with IBM SPSS, v.19.0. Descriptive statistics were used to characterise the sample and the frequency and intensity of emotional reactions. To calculate the frequency of emotions, responses on visual analogue scales were recoded (Not felt $=0 ;$ Felt $=1-100)$. To better describe the intensity of emotions (goal one), descriptive statistics were calculated considering only the participants who reported having felt each emotion. Differences in the frequency of emotions were evaluated with Cochran's Q test; post-hoc analyses were conducted with McNemar's test using the Bonferroni correction. Differences in the intensity of emotions were evaluated with a repeated-measures ANOVA complemented with post-hoc tests using the Bonferroni correction. 
A hierarchical agglomerative clustering analysis [Furthest Neighbour (Complete Linkage) method] was performed to evaluate the existence of distinct patterns of emotional reactions to the diagnosis. Cluster analysis is an exploratory and multivariate data analysis technique that assembles subjects in homogeneous groups regarding certain common characteristics (in this case, emotional reactions after a DCA). Subjects in the same cluster are similar regarding those characteristics and different from subjects belonging to other clusters. The chi-squared was used to measure the distance between individual observations of the clustering variables (i.e., emotional reactions). The number of clusters was selected based on the rescaled distances evident in the hierarchical cluster dendograms and the percentage change in agglomeration coefficients at each step of the cluster analysis (a substantial increase in the agglomeration coefficient indicates that 2 very different clusters are combined, suggesting it is a stopping point) (Hair \& Black, 2000). To characterise the cluster solution (i.e., which differences exist between clusters regarding the intensity of emotions), a MANOVA was performed, followed by univariate ANOVAs.

Gender differences of intensity of emotions and psychopathological symptoms (GDI) were assessed using a repeated-measures MANOVA and a paired-samples $t$-test. The couple was considered as a unit (the database was restructured to consider each couple as the subject of the analysis and each partner's score as a different variable) to account for the interdependency of a couple's observations (as they share the same experience regarding, for example, disclosure of the DCA) and to allow the investigation gender differences within the couple. Gender differences in the number of participants in each cluster were assessed with chi-squared tests. The frequency of both members of the couple belonging to the same clusters was also calculated. 
To address the last goal, multiple linear regressions were performed to investigate the role of cluster profiles of intensity of emotions (dummy code: 0:cluster_2; 1:cluster_1) on psychopathological symptoms (GDI) for mothers and fathers.

Significance was defined as $p<.05$, but marginally significant effects are also reported $(p<.10)$. Post-hoc power calculations made for all statistical analyses performed with a significance level of .10 , and power $\geq .80$ indicated that medium to large effects could be detected (Faul, Erdfelder, \& Lang, 2007). Effect-size measures are presented for all significant comparison analyses (small: $\eta^{2} \geq .01$, Cohen's $d \geq .20$; medium: $\eta^{2} \geq .06$, Cohen's d $\geq .50$; large: $\eta^{2} \geq .14$, Cohen's $d \geq .80$; Cohen, 1992).

\section{Results}

\section{Characterisation of parental emotional reactions at disclosure}

\section{Frequency and intensity of emotions}

Table 2 presents descriptive statistics on the frequency and intensity of emotions experienced at the disclosure.

\section{(Table_2_about_here)}

A significant difference was found regarding the frequency of different emotions [Cochran's $\left.\mathrm{Q}_{(9)}=354.05, p<.001\right]$. Post-hoc analyses (data not shown) revealed that the most frequent emotions were sadness, anxiety, hope, and shock. Less frequently reported than the first set of emotions were despair, and frustration, followed by anger and guilt. A significantly smaller number of participants felt relief and shame, when compared with the first and the second sets of emotions. Regarding the intensity of emotions, a significant difference was also found $\left[F_{(9)}=94.05, p<.001, \eta^{2}=.514\right]$. 
Post-hoc analyses revealed a pattern similar to that concerning the frequency of emotions: the most frequent emotions were also the most intense ones (data not shown).

\section{Patterns of emotional reactions}

A two-cluster solution was selected as better representing the data, generating distinct profiles of intensity of parental emotional reactions (Table 3). A multivariate effect was found when comparing the intensity of emotions according to cluster profiles (Pillai's Trace $=.752, F_{(10,79)}=23.992, p<.001, \eta^{2}=.752$ ). Follow-up univariate analyses (Table 3) showed that cluster_1 participants had significantly more-intense negative emotional reactions than the participants of cluster_2. No differences were found in positive emotions (relief and hope). According to their specificities, the two clusters can be identified as "higher intensity negative reactions" (cluster_1, $n=46$ ) and "lower intensity negative reactions" (cluster_2, $n=44)$. Effect size measures indicated that frustration, despair, anger and shock were the emotions that most contributed to group differentiation.

(Table_3_about_here)

\section{Gender differences on parental emotional reactions at disclosure}

No gender differences were found regarding the intensity of emotions experienced (Pillai's Trace $\left.=.332, F_{(10,30)}=1.49, p=.191\right)$. No differences were found in the percentage of male and female participants belonging to each cluster (Table 3). In $57.5 \%$ of cases, both members of the couple belonged to the same cluster $(32.5 \%$ to cluster_1; 25\% to cluster_2).

Emotional reactions at disclosure and post-diagnosis psychopathological symptoms 
Mothers $[M(S D)=18.29(13.77)]$ presented significantly higher levels of psychopathological symptoms than fathers $\left[M(S D)=13.07(11.96), t_{(40)}=3.011, p=\right.$ $.004, d=.40]$. For mothers, the model for the GDI was not significant $\left(F_{(1,46)}=2.364, p\right.$ $=.131$ ), suggesting that maternal psychopathological symptoms were independent of emotional reactions at disclosure. Conversely, for fathers, more-intense emotional reactions at disclosure (cluster_1; $\beta=.385, t=2.572, p=.014$ ) were significantly associated with higher levels of psychopathological symptoms $\left(F_{(1,38)}=6.617, p=.014\right.$, Adjusted $\left.R^{2}=.126\right)$.

\section{Discussion}

The present study showed that parents experience negative emotions, and also hope, with great intensity after the disclosure of the DCA. The more frequent and intense negative emotions (shock, sadness, and anxiety, followed by anger, guilt, frustration, and despair) were broadly congruent with acute grief reactions (Statham et al., 2000). This was expected because these emotions represent the parental response to the loss of their representation of a healthy infant. Contrarily, the high frequency and intensity of hope was an unexpected result, considering previous research, and supports the idea of emotional ambivalence at the time of the diagnosis (Graungaard \& Skov, 2007). Although parents' hope in the face of a DCA may be interpreted by health professionals as difficulty accepting the diagnosis, some studies with parents of disabled children suggest that hope in the future does not constitute a withdrawal from reality, but an important feature which may be beneficial for parents' healthy functioning and wellbeing (Kearney \& Griffin, 2001; Larson, 1998).

Beyond confirming our first hypothesis, these results also suggest variability in the emotional reactions to the diagnosis. In fact, despite their exploratory nature, our 
findings suggest that emotional reactions to the diagnosis can be described by two distinct profiles: "High intensity negative reactions" and "Lower intensity negative reactions". The first profile was characterised by negative emotional reactions of greater intensity, and fits the pattern of acute grief reactions commonly described in the literature (e.g. Chaplin et al., 2005; Kerr \& McIntosh, 1998). Conversely, the "Lower intensity reactions" profile was composed of negative reactions of minor intensity, which does not fit the pattern of acute grief reactions. If minor intensity reactions denote the absence of an acute grieving response after the DCA, the conceptualisation of the DCA as a loss may not apply to all parents; this will be a key-dimension in structuring counselling interventions after the DCA and should be further explored. Although it was not the focus of our study, another important issue to be further studied concerns factors (e.g., parity, type of congenital anomaly, socio-demographic characteristics) predicting the variability of parental emotional reactions. This information may help health professionals to better understand emotional reactions at disclosure and also to anticipate how parents will react at disclosure, adjusting their strategies for better communication.

The absence of gender differences in emotional reactions did not support our third hypothesis. This may relate to the fact that the emotional experience of parents (how much they felt each emotion), rather than its manifestations (how much they expressed each emotion), was assessed. This explanation is consistent with gender differences found in psychopathological symptoms. Gender differences found on psychopathological symptoms support the concept of incongruent grief (Goldbach et al., 1991; Lang et al., 2001), which holds that women tend to express more their suffering, with overt manifestations of psychopathological symptoms, while usually display greater emotional control. Considering these results, there is a conclusion that we 
consider to be essential: gender differences are related not to the way mothers and fathers feel about this event (DCA), but rather to their overt expressions and manifestations about it. This is also consistent with the information that both members of the couple presented similar patterns of emotional reactions in the majority of cases, suggesting similar intracouple experiences.

Our results also partially confirmed our last hypothesis, showing the influence of higher intensity reactions (cluster_1) on paternal post-diagnosis psychopathological symptoms. For mothers, there seem to be more difficulties in adjustment during the post-diagnosis stage, regardless of their initial reactions. One possible explanation is that usually the mother is more often confronted with problems related to the infant's medical condition (because there may be a greater monitoring of the pregnancy, and because the mother usually is the primary caregiver after the infant's birth; e.g., Hunfeld, Tempels, Passchier, Hazebroek, \& Tibboel, 1999).

\section{Strengths and limitations}

The inclusion of fathers, which allowed us to consider the paternal experience separately, and our quantitative approach, which differentiated between frequency and intensity of emotional experience, make this study a significant contribution to the field. However, some limitations should be acknowledged. The first is the retrospective assessment of emotional reactions to the diagnosis, along with the average return time of the questionnaires, indicating that there was some variability in the time elapsed after the diagnosis (1 -2 months after the diagnosis), which should be considered. Although the assessment timing was guided by ethical considerations, the possibility remains that parents' answers were influenced by their subsequent reinterpretations of the situation. However, previous research has shown that parents describe their reactions to the 
diagnosis in great detail, even if retrospectively (Drotar et al., 1975). Additionally, despite some variability in the time elapsed since the diagnosis until the delivery of questionnaires, our results on psychological distress after a DCA are similar to previous studies with assessments at one week (Brosig et al., 2007), one month (Doherty et al., 2009), and 8-10 weeks (Brisch et al., 2003) after the diagnosis. As such, we consider that this variability does not significantly compromise our results.

Second, the use of visual analogue scales to assess parental emotional reactions should be noted. This was due to the absence, to our knowledge, of specific instruments to assess the range of emotions that emerged from the literature review concerning the emotional experience and not its manifestations. Additionally, we did not assess whether participants felt emotions other than those emotions included in our scale. Third, the sample size is small, which may hinder the identification of small effects of variables (e.g., gender). In addition, ethical constraints prevented us from collecting socio-demographic and clinical data (regarding the infant's DCA) of non-participants. As such, despite having used a consecutive sampling technique, it is not possible to completely ensure the representativeness of the sample.

\section{Clinical implications}

As most parents are unprepared for receiving the news of a DCA (Lalor \& Begley, 2006), they may perceive their emotional reactions at disclosure as frightening and disturbing, and contrasting with the predominantly positive emotions that characterise the birth of an infant. In this context, it may be beneficial to provide psychoeducation to parents about the most common emotional reactions to the DCA and their variability, so they can feel validated in their emotional experience. 
Despite the predominance of negative emotions, results on hope should not be overlooked. Health professionals should provide factual and truthful information about the DCA, leaving room not only for negative but also for positive parental emotions, like hope or optimism (Kearney \& Griffin, 2001), which may constitute a resource that allows parents to continue facing the future (Larson, 1998). The non-recognition by health professionals of the possibility of positive emotions associated with the diagnosis establishes a deterministic view, which can undermine the mobilization of resources to deal with the situation (Dale et al., 2011).

The evaluation of parental emotional reactions at disclosure enables health professionals to adjust their communication strategies to the circumstances, namely regarding the information about the diagnosis. For example, when participants display more-intense emotional reactions, only essential information about the diagnosis should be provided because the ability to retain and understand information can be disrupted by overly-intense emotions. Other follow-up appointments should be set to provide additional information, to clarify doubts and to seek feedback of what was understood by the parents about the diagnosis (Aite, et al., 2004). As this was an unexplored topic, future research should investigate the effectiveness of different health professionals' strategies (e.g., regarding the communication of the DCA, the available time for decisions, and the information provided about the nature of emotional reactions at disclosure) as a function of different patterns of parental emotional reactions after a DCA.

Additionally, although in most couples both members displayed a similar pattern of emotional reactions to the DCA, there were cases where significant differences arose. Considering this, the evaluation of emotional reactions at disclosure also enables the early identification of intracouple incongruent experiences after a DCA, which may be 
an additional stressor for couples and should be dealt with. Also, gender differences on psychopathological symptoms can lead to intracouple difficulties (specifically, women may interpret the fewer psychopathological manifestations of their partners as an absence of suffering). Providing psychoeducation about the nature of these differences (i.e., explaining that they are not related with how each one feels about the event, but rather with how each one chooses to manifest their emotions) may constitute an important contribution in helping couples to go through this period in a more adaptive way.

Furthermore, results regarding gender differences indicate that the paternal experience should not be ignored by health professionals. Because fathers are more likely to contain their emotional expression to assume a protective role of their partners (Locock \& Alexander, 2006), it is important to assess whether this is hindering proper emotional expression. The opportunity to express emotions in a safe and nonthreatening environment should be given to both parents, as a couple and individually.

Finally, results also suggest that both fathers with high intensity emotional reactions at disclosure and mothers (regardless of their initial reactions) should be given particular attention, as they tend to present more adjustment difficulties in the early post-diagnosis stage, and, as such, are more prone to display a poorer adjustment in later evaluations (e.g., Skari et al., 2006). However, we should note that both emotional reactions at the disclosure and psychopathological symptoms should not be considered as indicators of maladjustment by themselves. They should be considered by health professionals, in the context of a more comprehensive assessment of other individual risk/protective factors for maladjusted responses (e.g., previous history of psychological problems, social support). After a comprehensive assessment, high-risk situations for maladjusted responses should be targeted for specialised counselling. 
In conclusion, the results of this study provide a more comprehensive characterisation of emotional reactions to the DCA, stressing its variability, which is reflected in the existence of different patterns of intensity of the reactions. The gender similarities and differences found also underscore the need for health professionals to take into account both the maternal and paternal experiences when adjusting their practice to meet parental needs.

\section{References}

Aite, L., Trucchi, A., Nahom, A., Casaccia, G., Zaccara, A., Giorlandino, C., \& Bagolan, P. (2004). Antenatal diagnosis of diaphragmatic hernia: Parents' emotional and cognitive reactions. Journal of Pediatric Surgery, 39(2), 174-178. doi:10.1016/j.jpedsurg.2003.10.010

Aite, L., Zaccara, A., Nahom, A., Trucchi, A., Iacobelli, B., \& Bagolan, P. (2006). Mothers' adaptation to antenatal diagnosis of surgically correctable anomalies. Early Human Development, 82, 649-653. doi:10.1016/j.earlhumdev.2005.12.010

Aite, L., Zaccara, A., Trucchi, A., Nahom, A., Iacobelli, B., \& Bagolan, P. (2006). Parents' informational needs at the birth of a baby with a surgically correctable anomaly. Pediatric Surgery International, 22, 267-270. doi:10.1007/s00383$005-1631-2$

Boyle, F. M., Vance, J. C., Najman, J. M., \& Thearle, M. J. (1996). The mental health impact of stillbirth, neonatal death or SIDS: Prevalence and patterns of distress among mothers. Social Science and Medicine, 43(8), 1273-1282. doi:10.1016/0277-9536(96)00039-1

Brisch, K. H., Munz, D., Bemmerer-Mayer, K., Terinde, R., Kreienberg, R., \& Kächele, H. (2003). Coping styles of pregnant women after prenatal ultrasound screening 
for fetal malformation. Journal of Psychosomatic Research, 55, 91-97. doi:10.1016/S0022-3999(02)00572-X

Brosig, C. L., Whitstone, B. N., Frommelt, M. A., Frisbee, S. J., \& Leuthner, S. R. (2007). Psychological distress in parents of children with severe congenital heart disease: The impact of prenatal versus postnatal diagnosis. Journal of Perinatology, 27, 687-692. doi:10.1038/sj.jp.7211807

Canavarro, M. C. (2007). Inventário de sintomas psicopatológicos - BSI: Uma revisão crítica dos estudos realizados em Portugal [Brief Symptom Inventory: A critical revision of Portuguese studies]. In M. R. Simões, M. Machado, M. Gonçalves, \& L. S. Almeida (Eds.), Avaliação psicológica: Instrumentos validados para a população portuguesa [Psychological assessment: Portuguese validated measures] (Vol. III, pp. 305-330). Coimbra: Quarteto Editora.

Chaplin, J. P., Schwitzer, R., \& Perkoulidis, S. A. (2005). Experiences of prenatal diagnosis of spina bifida or hydrocephalus in parents who decide to continue with their pregnancy. Journal of Genetic Counseling, 14(2), 151-162. doi:10.1007/s10897-005-0488-9

Cohen, J. (1992). A power prime. Psychological Bulletin, 112(1), 155-159. doi:10.1037/0033-2909.112.1.155

Dale, M. T., Solberg, O., Holmstrom, H., Landolt, M. A., Eskedal, L. T., \& Vollrath, M. E. (2011). Mothers of infants with congenital heart defects: Well-being from pregnancy through the child's first six months. Quality of Life Research. doi:10.1007/s11136-011-9920-9

Doherty, N., McCusker, C., Molloy, B., Mulholland, C., Rooney, N., Craig, B., ... Casey, F. (2009). Predictors of psychological functioning in mothers and fathers 
of infants born with severe congenital heart disease. Journal of Reproductive and Infant Psychology, 27(4), 390-400. doi:10.1080/02646830903190920

Drotar, D., Baskiewicz, A., Irvin, N., Kennell, J., \& Klaus, M. (1975). The adaptation of parents to the birth of an infant with a congenital malformation: A hypothetical model. Pediatrics, 56(5), 710-717.

European Surveillance of Congenital Anomalies. (2009). EUROCAT guide 1.3 and reference documents: Instructions for the registration and surveillance of congenital anomalies. Newtonabby, County Antrim: EUROCAT Central Registry.

Faul, F., Erdfelder, E., \& Lang, A. G. (2007). G*Power3: A flexible statistical power analysis program for the social, behavioral, and biomedical sciences. Behavior Research Methods, 39, 175-191.

Fonseca, A., \& Canavarro, M. C. (2010). Reacções parentais ao diagnóstico perinatal de anomalia congénita do bebé: Implicações para a intervenção dos profissionais de saúde [Parental reactions to perinatal congenital anomaly diagnosis of the baby: Implications for the intervention of health professionals]. Psicologia, Saúde \& Doenças, 11(2), 281-295.

Graungaard, A. H., \& Skov, L. (2007). Why do we need a diagnosis? A qualitative study of parents' experiences, coping and needs, when the newborn child is severely disabled. Child: Care, Health \& Development, 33(3), 296-307. doi:10.1111/j.1365-2214.2006.00666.x

Goldbach, K., Dunn, D., Toedter, L., \& Lasker, J. (1991). The effects of gestational age and gender on grief after pregnancy loss. American Journal of Orthopsychiatry, 61(3), 461-467. doi:10.1037/h0079261 
Griffin, T. (2002). Supporting families of infants with congenital heart disease. Newborn and Infant Nursing Reviews, 2(2), 83-89. doi:10.1053/nbin.2002.33051

Hair, J. F., \& Black, W. C. (2000). Cluster analysis. In L. Grimm, \& P. R. Yarnold (Eds.), Reading and understanding more multivariate statistics (pp. 147-205). Washington, D.C.: American Psychological Association.

Howard, E. (2006). Family-centered care in the context of fetal abnormality. Journal of Perinatal \& Neonatal Nursing, 20(3), 237-242.

Hunfeld, J., Tempels, A., Passchier, J., Hazebroek, F., \& Tibboel, D. (1999). Parental burden and grief one year after the birth of a child with a congenital anomaly. Journal of Pediatric Psychology, 24(6), 515-520. doi:10.1093/jpepsy/24.6.515

Johansson, B., \& Ringsberg, K. C. (2004). Parents' experiences of having a child with cleft lip and palate. Journal of Advanced Nursing, 47(2), 165-173. doi:10.1111/j.1365-2648.2004.03075.x

Jones, S., Statham, H., \& Solomou, W. (2005). When expectant mothers know their baby has a fetal abnormality: Exploring a crisis of motherhood through qualitative data-mining. Journal of Social Work Research and Evaluation, 62(2), 195-206.

Kearney, P., \& Griffin, T. (2001). Between joy and sorrow: Being a parent of a child with a developmental disability. Journal of Advanced Nursing, 34(5), 582-592.

Kerr, S., \& McIntosh, J. (1998). Disclosure of disability: Exploring the perspective of parents. Midwifery, 14, 225-232. doi:10.1016/S0266-6138(98)90094-8

Lalor, J., \& Begley, C. (2006). Fetal anomaly screening: What do women want to know? Journal of Advanced Nursing, 55(1), 11-19. doi:10.1111/j.13652648.2006.03884.x 
Lalor, J., Begley, C., \& Galavan, E. (2009). Recasting hope: A process of adaptation following fetal anomaly. Social Science \& Medicine, 68, 462-472. doi:10.1016/j.socscimed.2008.09.069

Lang, A., Gottlieb, L., \& Amsel, R. (1996). Predictors of husbands' and wives' grief reactions following infant death: The role of marital intimacy. Death studies, 20, 33-57. doi: 10.1080/07481189608253410

Larson, E. (1998). Reframing the meaning of disability to families: The embrace of paradox. Social Science \& Medicine, 47(7), 865-875. doi:10.1016/S02779536(98)00113-0

Locock, L., \& Alexander, J. (2006). Just a bystander? Men's place in the process of fetal screening and diagnosis. Social Science \& Medicine, 62, 1349-1359. doi:10.1016/j.socscimed.2005.08.011

Marshak, L. E., \& Prezant, F. (2007). Married with special-needs children: A couples' guide to keeping connected. Bethesda: Woodbine House.

Mazer, P., Gischler, S. J., Koot, H. M., Tibboel, D., Dijk, M. v., \& Duivenvoorden, H. J. (2008). Impact of a child with congenital anomalies on parents (ICCAP) questionnaire: A psychometric analysis. Health and Quality of Life Outcomes, 6(102), 102-110. doi:10.1186/1477-7525-6-102

Mitchell, L. (2004). Women's experiences of unexpected ultrasound findings. Journal of Midwifery \& Women's Health, 49(3), 228-234. doi:10.1016/j.wombi.2010.01.001

Nusbaum, R., Grubs, R., Losee, J., Weidman, C., Ford, M., \& Marazita, M. (2008). A qualitative description of receiving a diagnosis of clefting in the prenatal or postnatal period. Journal of Genetic Counseling, 17, 336-350. doi:10.1007/s10897-008-9152-5 
Petrucelli, N., Walker, M., \& Schorry, E. (1998). Continuation of pregnancy following the diagnosis of a fetal sex chromossome abnormality. Journal of Genetic Counseling, 7(5), 410-415. doi:10.1023/A:1022828715158

Schuth, W., Karck, U., Wilhelm, C., \& Reisch, S. (1994). Parents' needs after ultrasound diagnosis of a fetal malformation: An empirical deficit analysis. Ultrasound in Obstetrics and Gynecology, 4, 124-129. doi:10.1046/j.14690705.1994.04020124.x

Skari, H., Malt, U., Bjornland, K., Egeland, T., Haugen, G., Skreden, ..., \& Emblem, R. (2006). Prenatal diagnosis of congenital malformations and parental psychological distress: A prospective longitudinal cohort study. Prenatal Diagnosis, 26, 1001-1009. doi:10.1002/pd.1542

Sommerseth, E., \& Sundby, J. (2010). Women's experiences when ultrasound examinations give unexpected findings in the second trismester. Women and Birth, 23, 111-116. doi:10.1016/j.wombi.2010.01.001

Statham, H., Solomou, W., \& Chitty, L. (2000). Prenatal diagnosis of fetal abnormality: Psychological efffects on women in low-risk pregnancies. Baillière's Clinical Obstetrics and Gynaecology, 14(4), 731-747. doi:10.1053/beog.2000.0108

Taanila, A., Syrjälä, L., Kokkonen, J., \& Järvelin, M.-R. (2002). Coping of parents with physically and/or intellectually disabled children. Child: Care, Health \& Development, 28(1), 73-86. doi:10.1046/j.1365-2214.2002.00244.x 
Table 1. Socio-demographic and clinical characterization of the sample

\begin{tabular}{|c|c|c|}
\hline $\begin{array}{c}\text { Total } \\
(N=93)\end{array}$ & $\begin{array}{l}\text { Mothers } \\
(n=51)\end{array}$ & $\begin{array}{l}\text { Fathers } \\
(n=42)\end{array}$ \\
\hline$n(\%)$ & $n(\%)$ & $n(\%)$ \\
\hline$M(S D)$ & $M(S D)$ & $M(S D)$ \\
\hline
\end{tabular}

\section{Demographics}

Age

$31.51(4.68)$

$31.14(4.93)$

31.95 (4.36)

$-.835 \quad .406$

Marital status

$\begin{array}{rccccc}\text { Married/Living together } & 86(92.5 \%) & 46(90.2 \%) & 40(95.2 \%) & & \\ \text { Single } & 5(5.4 \%) & 3(5.9 \%) & 2(4.8 \%) & 1.764 & .414 \\ \text { Divorced } & 2(2.2 \%) & 2(3.9 \%) & 0(0 \%) & & \end{array}$

\section{Education}

$$
13.59(3.48)
$$

$14.39(3.4)$

$12.62(3.38)$

$2.512 \quad .014$

Employment status

$\begin{array}{cccccc}\text { Employed } & 83(89.1 \%) & 43(84.3 \%) & 40(95.2 \%) & & \\ \text { Unemployed } & 10(10.8 \%) & 8(15.7 \%) & 2(4.8 \%) & & .091\end{array}$

\section{Clinical}

\section{Parity}

Primiparity

Multiparity

Timing of diagnosis

Prenatal diagnosis

[Gestational age at diagnosis: $M(S D)=23.18(5.12)$ weeks]

Postnatal diagnosis

Congenital anomalies

Urinary system anomalies

Nervous system anomalies

Congenital heart disease
$34(60.8 \%)$

$17(39.2 \%)$

$39(76.5 \%)$

$12(23.5 \%)$

$15(29.4 \%)$ [14 (93.3\%) prenatally diagnosed]

$8(15.7 \%)$ [8 (100\%) prenatally diagnosed]

$11(21.6 \%)$ [4 (36.4\%) prenatally diagnosed] 
Digestive system anomalies

Visible anomalies
$6(11.8 \%)$ [6 (100\%) prenatally diagnosed]

$11(21.6 \%)$ [7 (63.6\%) prenatally diagnosed] 
Table 2. Parental emotional reactions to the diagnosis disclosure: Frequency and intensity

\begin{tabular}{rccc}
\hline & \multicolumn{2}{c}{ Frequency } & Intensity \\
\cline { 2 - 4 } Emotion & $n(\%)$ & Did not feel & $M(S D)$ \\
\hline Guilt & $46(49.5 \%)$ & $47(50.5 \%)$ & $50.26(35.41)$ \\
Anger & $46(49.5 \%)$ & $47(50.5 \%)$ & $56.48(37.59)$ \\
Sadness & $89(95.7 \%)$ & $4(4.3 \%)$ & $83.1(24.74)$ \\
Anxiety & $88(94.6 \%)$ & $5(5.4 \%)$ & $80.2(26.14)$ \\
Shock & $80(86.0 \%)$ & $23(14.0 \%)$ & $73.05(31.52)$ \\
Despair & $68(73.9 \%)$ & $24(26.1 \%)$ & $58.32(34.79)$ \\
Shame & $19(20.4 \%)$ & $74(79.6 \%)$ & $30.37(29.09)$ \\
Relief & $21(22.6 \%)$ & $72(77.4 \%)$ & $39.05(36.95)$ \\
Frustration & $54(59.3 \%)$ & $37(40.7 \%)$ & $64.43(35.21)$ \\
Hope & $90(96.8 \%)$ & $3(3.2 \%)$ & $78.69(26.42)$ \\
\hline
\end{tabular}


Table 3. Cluster profiles of parental emotional reactions: Between-groups differences regarding intensity, and frequency by gender

\begin{tabular}{|c|c|c|c|c|c|}
\hline & Group 1 & Group 2 & & & \\
\hline & "Higher intensity & "Lower intensity & & & \\
\hline & negative & negative & & & \\
\hline & reactions" & reactions" & & & \\
\hline & $(n=46)$ & $(n=44)$ & & & \\
\hline Emotion & $M(S D)$ & $M(S D)$ & $F_{(1,70)}$ & $p$ & $\eta^{2}$ \\
\hline Guilt & $38.11(38.22)$ & $10.25(24.38)$ & 16.822 & $<.001$ & .160 \\
\hline Anger & 49.85 (41.49) & $4.5(13.56)$ & 47.652 & $<.001$ & .351 \\
\hline Sadness & $90.67(15.35)$ & $68.57(35.07)$ & 15.230 & $<.001$ & .148 \\
\hline Anxiety & $86.52(19.20)$ & $65.2(36.61)$ & 12.119 & .001 & .121 \\
\hline Shock & $83.48(24.84)$ & $43.05(39.02)$ & 34.710 & $<.001$ & .283 \\
\hline Despair & $68.61(30.23)$ & $16.14(27.83)$ & 73.222 & $<.001$ & .454 \\
\hline Shame & $10.11(19.97)$ & $0.09(0.473)$ & 11.058 & .001 & .112 \\
\hline Relief & 4.63 (13.83) & $13.61(31.06)$ & 3.189 & .078 & .035 \\
\hline Frustration & $72.48(31.32)$ & $3.07(9.09)$ & 199.916 & $<.001$ & .694 \\
\hline Hope & 71.13 (26.93) & $81.82(30.251)$ & 3.14 & .080 & .034 \\
\hline Gender & $n(\%)$ & $n(\%)$ & $\chi^{2}$ & $p$ & \\
\hline Female & $27(58.7 \%)$ & $22(44.9 \%)$ & \multirow[b]{2}{*}{.686} & \multirow[b]{2}{*}{.408} & \\
\hline Male & $19(46.3 \%)$ & $22(53.7 \%)$ & & & \\
\hline
\end{tabular}


